\title{
Optimization of the supply chain through decision models in aggregate planning
}

\section{Optimización de la cadena de suministro a través de modelos de decisión en la planeación agregada}

\author{
MUÑOZ-HERNANDEZ, Raquel †* \& RANGEL-LARA, Saúl \\ Universidad Politécnica del Valle de México, Dirección de Ingeniería Industrial. \\ ID $1^{\text {st }}$ Author: Raquel, Muñoz Hernández / ORC ID: 0000-0002-4461-8027, Researcher ID Thomson: \\ I-6661-2018, arXiv ID Author: Raquel4, CVU CONACYT ID: 1001913 \\ ID $1^{\text {st }}$ Co-author: Saúl, Rangel Lara / ORC ID: 0000-0003-1498-340X, arXiv ID Author: Dr.SaulRangel, CVU CONACYT \\ ID: 103670
}

DOI: $10.35429 / J M P C .2020 .18 .6 .33 .39$

Received: July 25; Accepted: December 30, 2020

\begin{abstract}
The study consists of the design of a decision analysis model for the supply chain, based on the Aggregate Planning strategies; the present investigation is of a transversal exploratory type. This arises from the need for Pymes and MiPymes to carry out a correct scheduling of purchases for the supply of products in its three basic levels from the supplier to the end customer. The objective of this project is to present a model that allows reducing the level of risk in supply chains using aggregate planning tools and decision analysis. The decision analysis model designed based on uncertainty will serve as a general plan for operations and will establish the parameters within which it would facilitate the performance of the supply chains of Pymes, allowing to improve capacity distributions. Therefore, it is important to execute the aggregate plans in a very broad scope of the chain, as proposed in the model proposed and applied in a Pyme company, with adequate and promising results.
\end{abstract}

Supply, Risk, Uncertainty, Shortage

\begin{abstract}
Resumen
Esta investigación es el resultado de 3 investigaciones El estudio consiste en el diseño de un modelo de análisis de decisiones para la cadena de suministro, con base en las estrategias de Planeación Agregada; la presente investigación es de tipo exploratorio transversal. Esto surge de la necesidad de las Pymes y MiPymes de realizar una correcta programación de las compras para el suministro de los en sus tres niveles básicos desde el proveedor hasta el cliente final. El objetivo de este proyecto es presentar un modelo que permita reducir el nivel de riesgo en las cadenas de suministro empleando herramientas de planeación agregada y análisis de decisiones. El modelo de análisis de decisión diseñado con base en la incertidumbre servirá como un plano general para las operaciones y establecerá los parámetros dentro de los cuales facilitaría el desempeño de las cadenas de suministro de las Pymes, permitiendo mejorar las distribuciones de la capacidad. Por tanto, es importante ejecutar los planes agregados en un ámbito muy amplio de la cadena, tal como se plantea en el modelo propuesto y aplicado en una empresa Pyme, con resultados adecuados y promisorios.
\end{abstract}

Suministro, Riesgo, Incertidumbre, Escasez

Citation: MUÑOZ-HERNANDEZ, Raquel \& RANGEL-LARA, Saúl. Optimization of the supply chain through decision models in aggregate planning. Journal of Microfinance Planning and Control. 2020. 6-18:33-39.

\footnotetext{
* Correspondence to the Author (Email: raquel.munoz@upvm.edu.mx)

$\dagger$ Researcher contributing as first author.
} 


\section{Introduction}

Currently, the need to efficiently produce without delays in the delivery of a given product is a factor of utmost importance for companies that want to remain active in the current market, which requires quick responses and compliance in quality, quantity and delivery times. The above is much more critical when it comes to a small or medium-sized company than for it to face a very competitive world, with companies with higher technology and advanced organizational level, so they will be more productive, they will generate the same item at a lower price and with an immediate response time, consequently obtaining greater advantage and consumer preference, this situation has made many small and mediumsized enterprises (Pymes).

One of the main differences between large and small companies lies in the investments they make, especially in the development of materials and the innovation of machinery. However, the concept of compliance with the requirements of both purchasing and supplier companies is very similar, it only differs in technological developments and financing. More and more Pymess in the country are worrying about training, in order to obtain greater added value throughout their entire production chain, although microenterprises still have little participation. (Pinchi, \& Chomba 2020).

Among the factors that prevent an adequate and successful management of microenterprises, in this context of uncertainty and fear, is the lack of methods to carry out adequate planning of their inputs, which is why their inventories are out of supply or oversaturated, giving rise to losses. In resources or deliveries, also in the national context, supplies are affected by various factors such as the national economy, road infrastructure, crime, traffic, demonstrations, among others that can hinder deliveries and the traditional administrative planning process. it is deterministic without assessing the risk factor. (Correa, 2020).
As a study hypothesis, it is considered that a decision analysis model between aggregate planning and the Supply Chain that considers probabilistic factors such as risk assessment, will provide greater certainty in decision-making. Based on the above, in this research an analysis is made between the supply chain management process and the traditional Aggregate Planning methods in a comprehensive study for decision making.

\section{Problem statement}

In the case of Mexico, this sector constitutes around $99.8 \%$ of the industries nationwide. The foregoing takes on greater relevance the exceptional and difficult current situation in which the supply and supply have been affected, due to both internal and external factors, among which the following stand out: the pandemic, the high substitution of domestic products for imported items, the instability of the economic activity, the generalized decrease of the purchasing power of the population and consequently of the demand; the accumulation of debts with the bank and mainly, the deficiencies in the operation and management of a large number of Pymes and MiPymes. (Escudero, \& Ponce Vélez. 2020)

From October 2008 to November 2019, it was calculated that between $8 \%$ and $10 \%$ of Mexican SMEs had closed for this cause, later with the pandemic this has increased without being able to yet have exact figures; In addition, considering the lack of advice and professionalization, it prevents microenterprises from surviving. (IMSS, 2019)

This study shows the situation of SMEs in supply chains where Mexican micro, small and medium-sized enterprises (Pymes) represent between $85 \%$ and $90 \%$ of the entire private sector, so it is worth knowing its concept of supply chain: On several occasions, for this sector the supply chain does not mean more than the fulfillment of the operational requirements, both of the purchasing companies and the suppliers. According to Sánson (2012) "Staying oblivious to the issue can mean potential losses for them by falling behind in terms of the requirements of new or changing markets". 


\section{Objective}

Model an adequate management of Aggregate Planning that affects the good performance of the Supply Chain of Pymes.

\section{Definition of small and medium enterprises in Mexico}

To define what an Pyme is, there are different criteria and these vary in each country. In some cases, sales criteria are considered, another of employment, in others of assets. As is already known, in Mexico there is only one indicator or definition criterion: employment, however, the definition changes depending on the type of economic unit, that is, if it is industrial, commercial or services. Table 1 shows the classification according to the type of economic unit that distinguishes it.

\begin{tabular}{|l|r|r|r|}
\hline Size & Industry & Comerce & Services \\
\hline Micro & $1-10$ & $1-10$ & $1-10$ \\
\hline Little & $11-50$ & $11-30$ & $11-50$ \\
\hline Medium & $51-250$ & $31-100$ & $51-100$ \\
\hline Big & + de 251 & + de 100 & + de 100 \\
\hline
\end{tabular}

Table 1 Size of companies according to type of economic unit.

Here the participation of the main economic units in Mexico is defined more clearly, it should be noted that most of the economic units within the category, microenterprises are those that monopolize the economic system of the country (in terms of units). However, the study will focus on small and medium-sized companies in the manufacturing sector particularly, even though micro and small companies together generate just over $60 \%$ of employment and contribute close to $50 \%$ of the Gross Domestic Product (PIB).

The study focuses on the manufacturing company that is in need of seeking greater competitive advantage and added value for its products, this particularly in response to more aggressive competition.
The manufacturing industries are made up of economic units mainly dedicated to the mechanical, physical and chemical transformation of materials or substances, in order to obtain new products, maquila activities, the assembly of parts and components are also considered as part of manufacturing or manufactured products, the reconstruction of machinery, industrial, commercial, office and other equipment, heat treatments, furniture veneer and similar processes.

Importance of manufacturing industries

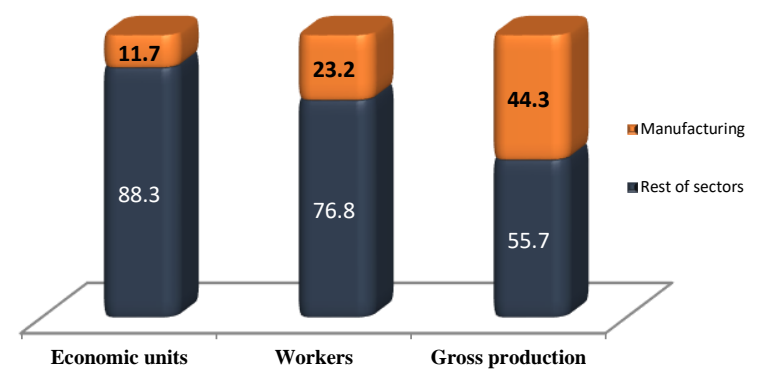

Figure 1 Importance of manufacturing industries

\section{Justification of the Study}

From this it can be commented that the majority of micro-enterprises that have unpaid personnel remain in the informal sector, so no income control is carried out due to this condition. The economic units and employed personnel registered in the manufacturing sector in the central zone of the country, the state of Mexico and in Mexico City concentrated $71.3 \%$ of the establishments, which employed $74.7 \%$ of the total employed personnel in the region and they contributed $69 \%$ of regional production.

Based on the foregoing, it is considered very important to provide small companies with elements of logistics and supply chain control based on aggregate planning and decision models, taking into account uncertainty for risk assessment.

\section{Methodology to develop}

Forecasts are the first step in the production planning process, the starting point for the development of strategic plans and allow companies to roughly visualize future events and largely eliminate uncertainty to react quickly to changing conditions with high degree of precision. 
In relation to the existing methods for the elaboration of aggregate plans according to the consulted authors, the most relevant ones are the qualitative methods such as: "executive committee consensus, Delfos method, survey of the sales force, survey of the clients, analogy of life cycles or historical analogy and method of market research. These methods are used when there is no history of demand. (Ballou, Ronald. \& Diaz. 2004)

Qualitative methods use mathematical and statistical procedures dividing into two types: time series methods and causal methods, both are used when there is a history of demand in the organization.

Qualitative methods use mathematical and statistical procedures that are used when there is a history of demand in the organization. The most frequent are: Linear regression, Least squares method, Moving averages, Weighted moving average, Exponential smoothing model, Exponential smoothing with trend.

Among the quantitative methods there is also the Aggregate Planning. (Heizer, \& Render 2004)

\section{Sample size}

For the present study, the application of the Aggregate Planning applied in a micro-company in the state of Mexico was considered, which consists of 10 workers among whom they can increase as the demand for the product increases.

The elaboration of the pure and combined strategies of the same was carried out and later the same data were applied for a Decision Model in simulation. (Chase \& Aquilano, 2018).

As a first step it was required:

- $\quad$ Determine the demand in each period.

- Determine the capacity for normal time, overtime and subcontracting in each period.

Find the costs of labor, hiring and firing, as well as the costs of holding inventories.

Consider company policy that applies to workers or inventory levels.
- Develop alternative plans and examine your total costs.

The research was carried out by studying a single process for the manufacture of a refrigerator since the research instruments and the tool to be used (aggregate planning) have multiple variables, so it is advisable to carry out the analysis in a single area that is significant in the production process and in which most of the variables that will intervene for the elaboration of the model are covered. (Latorre, 2020)

\section{Software specialized in decision analysis}

There are several specialized computer programs in the area of decision analysis, and for this case we used:

DPL (Decision Programming Language) - Create decision trees, influence diagrams, Monte Carlo simulation in problems with multiple attributes

This program helps to perform decision analysis and reduces the time and cost of developing decision models.

Because a comprehensive result is sought that covers most of the phases involved in a supply chain in a given time horizon; The tool to be used is Aggregate Planning between supply and production demand in the medium term up to approximately 18 months in the future. (Geary, Childerhouse \& Towill 2002)

To carry out the proposal of the Model, first an application by Pure and Mixed strategies will be shown with historical data of the case study.

The approach is to optimize by maximizing profits and minimizing costs. In short, only the initial restrictions and the tables of values obtained in each Aggregate Production Plan (PAP) are included, where all the proposals are medium-term, that is, six months of projection.

It is a formal decision analytical framework that explicitly defines the decisions and their alternatives, as well as the uncertainties and their results and the output metrics that are most important in making the decision. 
The relationships between the critical factors and the timing of the events that define the decision problem are explicitly defined. When analyzing the decision model, the alternative with the highest expected value of the output metric is indicated at each decision point, ensuring that the best strategy is followed, now and in the future, given the range of possible outcomes.

The intuition and transparency of the analytical decision process ensure that key stakeholders, analytical teams, and decision makers have a deeper understanding of the decision problem and the confidence to act in accordance with stated strategic directions. A DPL influence diagram represents all the components of a decision problem (decisions, uncertainties, and values) and the relationships between them. The Influence Diagram consists mainly of nodes and arcs of influence.

\section{Results}

In developing a strategy, all the important elements that make up the body of the decision situation must be considered. In the model there are sets of main nodes, which can be called the backbone of the situation, since there all the nodes of the model rest and are present in any particular situation of the decision family; the nodes that make up this structure are:

The Model consists of only one decision in this first stage.Diagnosis Result, is the first decision of the model, since the decision maker must think about the situation he faces, with the information obtained up to this node. This decision influences the preliminary study node, determining the continuity of the process.

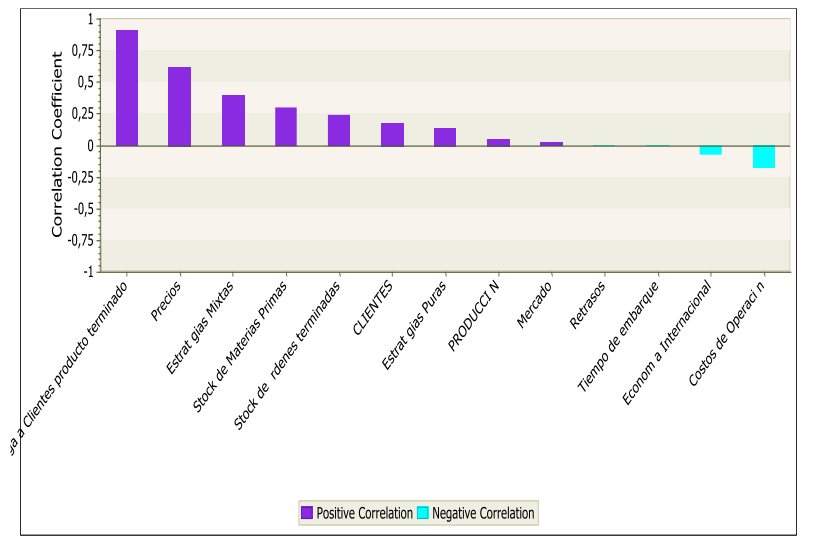

Figure 2 Overall result of the Aggregate Planning

The uncertainty nodes are relevant for the units sold node. The fundamental group is the one formed by the Strategies node, because it performs an analysis that projects the probabilistic behavior, calculating net sales, contribution margin and profits, among others; concluding with the investment node, a node that defines the continuity of the process.

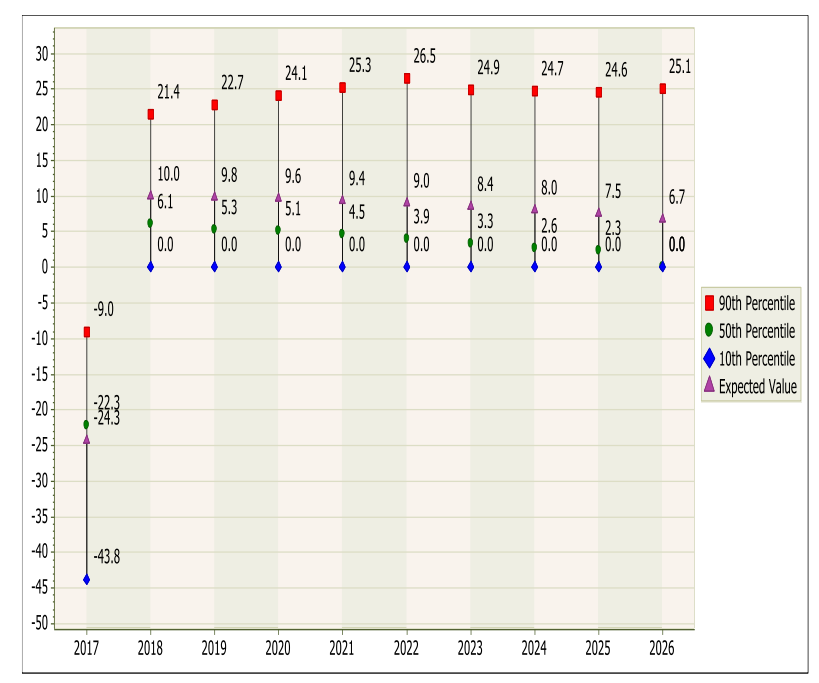

Figure 3 Six-year forecast 

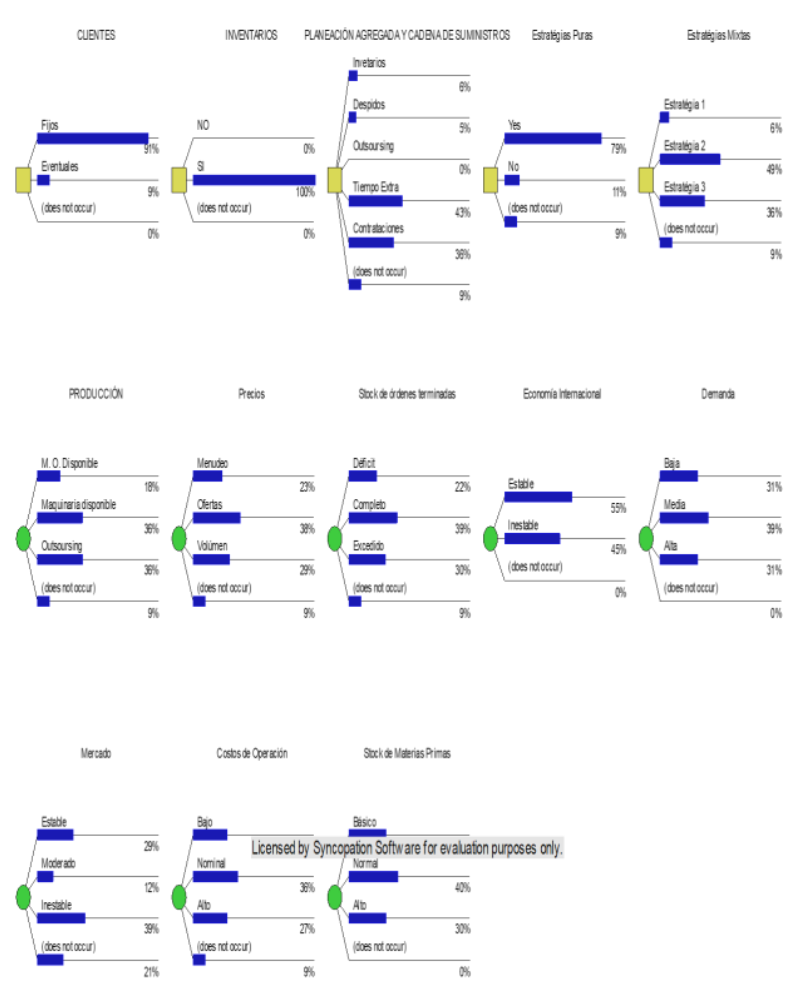

Figure 4 Results obtained from the application of the decision model in Strategic Planning and Supply Chain

Lastly, the Montecarlo simulation of the accumulated values is shown.

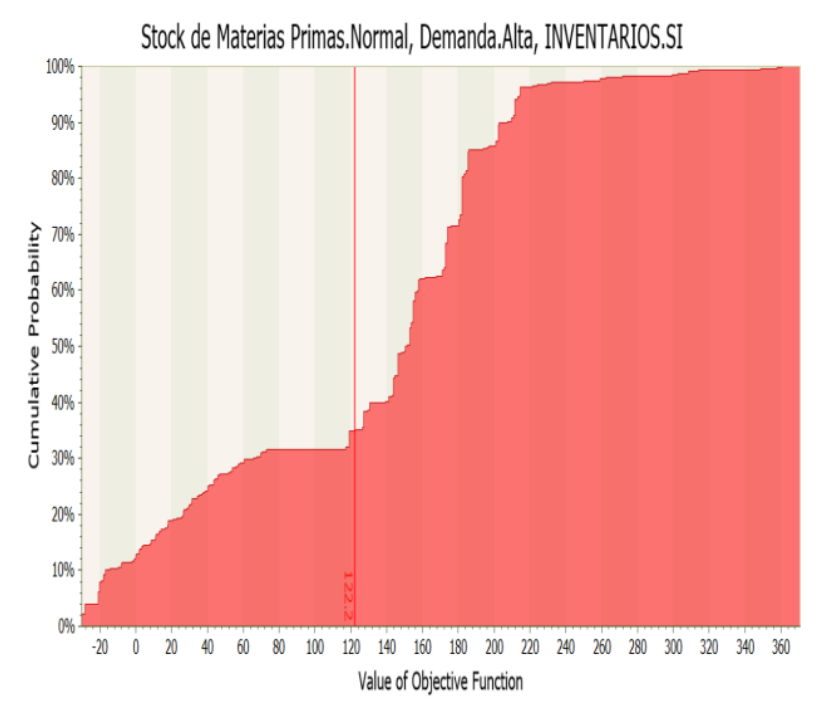

Figure 5 Monte Carlo simulation

\section{Conclusions}

A good decision is one that is consistent with the information that the decision maker can have at the time of making the decision; consistent with the decision-maker's perception of the future; consistent with the decision maker's preferences, goals, and objectives.
Therefore, the information that feeds the decision model is as valuable as the results themselves; that is, if the alternatives are creative and promising, it is very likely to choose valuable strategies and results; therefore it is important that the decision analyst guides the expert to always be creative in obtaining information that is provided to the model.

The decision model developed was properly adjusted, helping decision-makers and generating highly creative alternatives and obtaining optimal, highly relevant results.

At first it is difficult to see the benefits of the decision model, however when applying it the benefits of this discipline can be observed due to the results found; generating more application options in companies. Although the modeling of each project is relatively easy (due to the nature of the model), obtaining the information is difficult; as it requires greater input from experts.

In sum, the use of the decision model will allow greater perspectives with less time and effort than is invested without it. So the use and benefits of decision analysis can potentially be improved in the long term.

The elements and situations that were considered in the decision model are the most important in the family of anticipated decision situations; however, there are probably still elements to optimize for it to be more complete. The model can be updated as it is used.

\section{References}

Correa Chavarro, L. (2020). Estado del arte del desempeño social en las cadenas de abastecimiento en Colombia. México: Prentice Hall. China: Mc Graw-Hill Educación.

Chase, R. B., Jacobs, R. F., \& Aquilano, N. J. (2018). Administración de Operaciones. Producción y cadena de suministros (15 ed.). México, México: McGRAW-HILL

Chopra, S. M. (2017). Supply Chain Managemengt: Strategy, planning, and Operation. México Prentice Hall.

Ballou, Ronald H. \& Diaz. (2004). Logistica, Administración de la Cadena de Suministro. México. Prentice Hall

MUÑOZ-HERNANDEZ, Raquel \& RANGEL-LARA, Saúl. Optimization of the supply chain through decision models in aggregate planning. Journal of Microfinance Planning and Control. 2020 
Escudero Perla, Y. B., \& Ponce Vélez, S. A. (2020). Factores que influyeron en la optimización de la cadena de suministros de las empresas exportadoras e importadoras peruanas certificadas como Operadores Económicos Autorizados (OEA) durante los años 2013 al 2018.

Heizer, J. \& Render, B. (2004). Principio de Administración de Operaciones. México: Pearson Educación.

Geary S., Childerhouse P., and Towill D. (2002). Uncertainty and the seamless supply chain. Supply Chain Management Review, 5261.

INEGI Censos económicos (2019) Extraído 12 de noviembre 2020, de https://www.inegi.org.mx/programas/ce/2019/ \#: :text=Los\%20Censos\%20Econ\%C3\%B3mi cos $\% 20$ son $\% 20 \mathrm{el}$, mexicana $\% 20 \mathrm{en} \% 20 \mathrm{un} \% 20$ momento\%20determinado.

Latorre Vásquez, G. N. (2020). Cadena de suministro para disminuir los costos de importación de máquinas cosechadoras de la empresa importadora Alvarado EIRL-2018.

Pinchi Quispe, D. A., \& Chomba Amasifén, A. R. (2020). Evaluación de la gestión de almacenamiento y su relación con la cadena de abastecimiento de la empresa distribuidora, Almacenes Junior Max EIRL-Banda de Shilcayo, periodo 2018. 